\title{
التسويق الاكترونى وسبل تنمية الصادرات الزراعية المصرية
}

\author{
أمل الجابري(1) ، جابر بسيوني(2) ، الحسين الصيفي(1) ، أوليفيا صالح(1) \\ (1) قسم اقتصاد وإدارة الأعمال الزراعية - كلية الزراعة - جامعة الإسكندرية. \\ (2) قسم الإقتصاد الزراعي - كلية الزراعة (سابا باشا) - جامعة الإسكندرية.
}

Received: Nov. 19, 2017

Accepted: Dec. 30,2017

الملخص

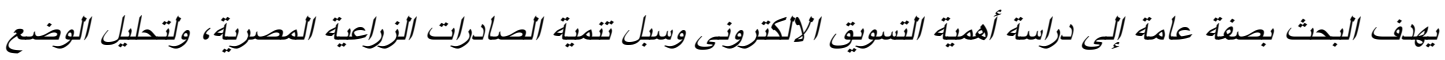

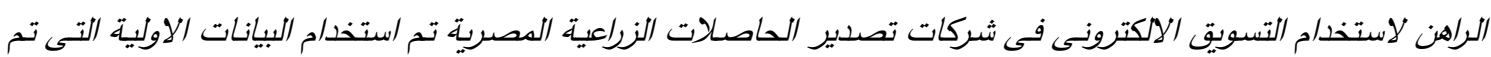

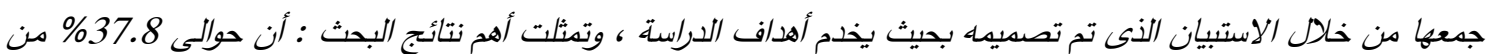

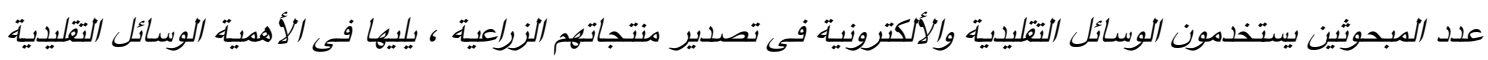

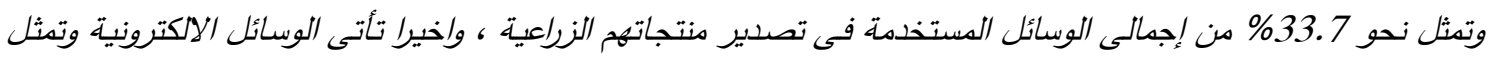

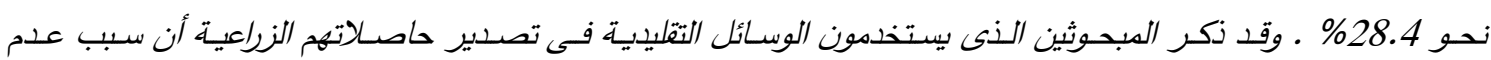
استخدامهم للوسائل الاكترونية فى تصدير حاصلاتهم النراعية يرجع الى عدم مناسبة الوسيلة الالكترونية إلى ما يتم تصديره،

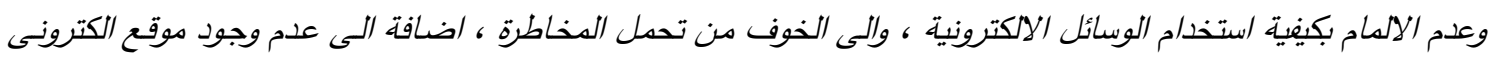

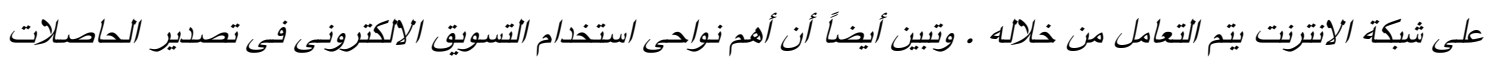

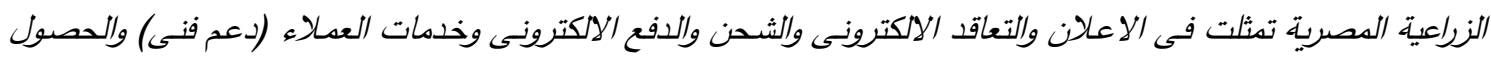
على معلومات عن العملاء والسلح ومختلف النواحى الخاصة بتصدير الحاصلات الزراعية ـ يتضح أن عدد الثركات الزراعية

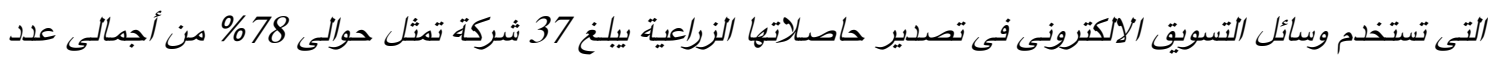
شركات عينة الدراسة التى تقوم بتصدير الحاصلات الزراعية.

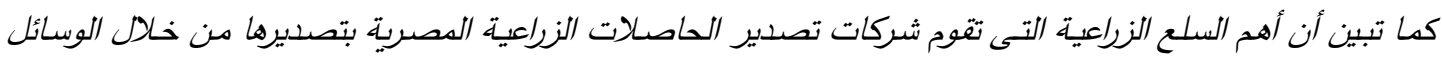

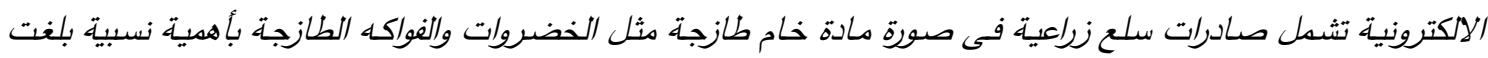

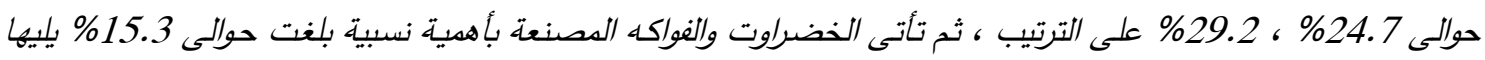
الأرز ثم النباتات الطبية والعطرية بنسب بلغت حوالى 12.3\% ، 18.5\% على الترتيب من إجمالى اصناف السلع النراعية التى تقوم شركات تصدير الحاصلات الزراعية بتصديرها من خلال الوسائل الالكترونية .

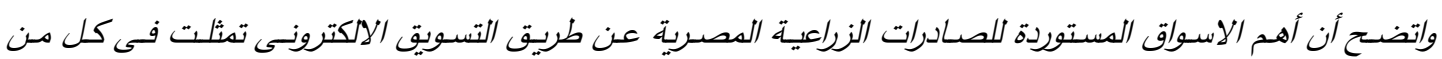

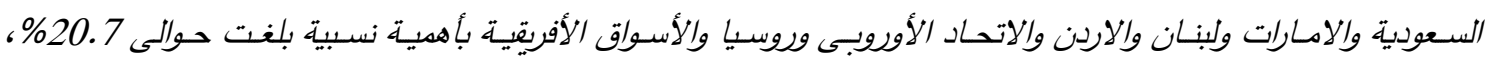
18.9\%، 16.9\% ، 15.1\% ، 14.2 \% ، 10.4 \% \% 3.8 على الترتيب ويتبين مدا سبق انخفاض الأهدية النسبية

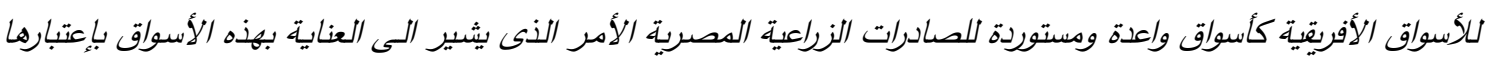

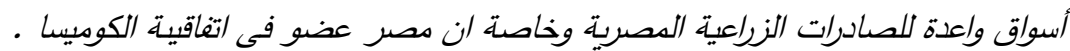
وقد تم حصر المشاكل الداخلية والخارجية التى تواجه شركات تصدير الحاصلات النراعية الدصرية عند استخدامها

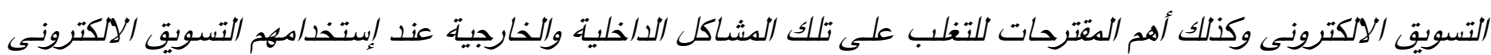

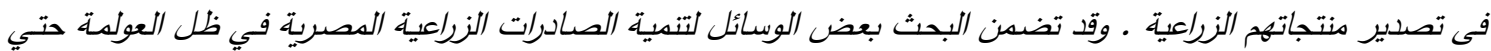
يمكنها منافسة الصادرات الدثيلة من الدول الدنافسة.

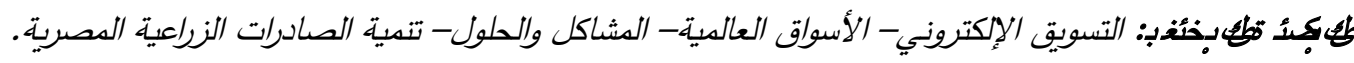


المشكلة البحثية

تتميزز التجـارة الخارجيـة الزراعيـة المصـرية بسـمات

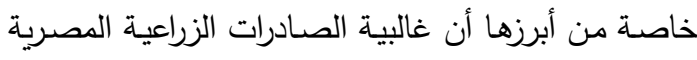

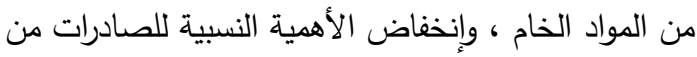

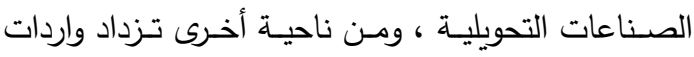

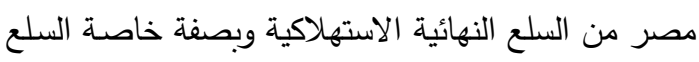

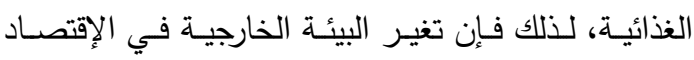

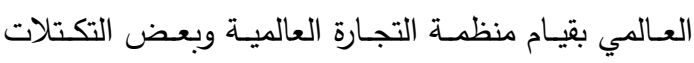
الاقتصـادية الأخرى يفرض واقعاً يشكل فى مجمله تحدياً للصـادرات الزراعية بصفة خاصـة ، ولذلك يبرز التساؤل التالي: ما هو مستقبل الصادرات الزراعية المصرية ووسائل تتميتها فى إطار العولمة ؟.

\section{الأهداف البحثية:}

إنطلاقـاً مـن المشكلة البحثيـة تهـدف الدراسـة بصـفة عامـة إلى دراسـة أهمية التسويق الإلكترونى وسبل تتميـة

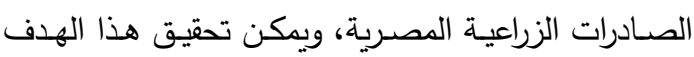
الرئيسي من خلال دراسة الأهداف الفرعية التالية :

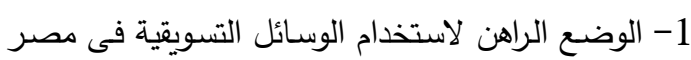

$$
\text { فى تصدير الحاصلات الزراعية. }
$$

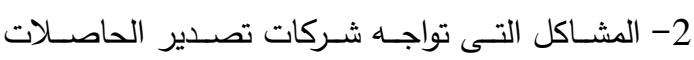

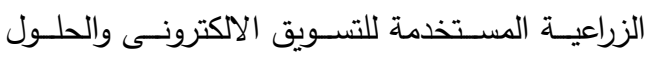

$$
\text { المقترحة. }
$$

3- سـبل تتميـة الصـادرات الزراعيـة المصـرية فـى ظـل

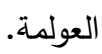

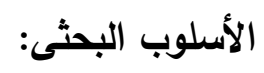

تحقيقاً لأهداف الدراسـة سيتم الإعتماد على التحليل الإقتصادي الوصفى والذى يتمثل فى استخدام الاسـاليب

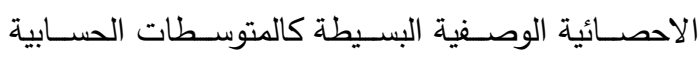
والنســب المئويـة ، لإبــراز الاهيــة النسـبية للمتغـرات الاقتصادية موضع الدراسة .
يعتبر التصدير أحد الركائز الأساسية التي يعتمد عليها

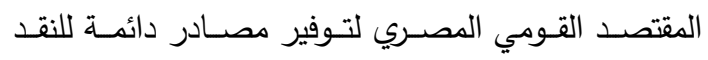
الأجنبى، حيث يمكن توظيف مـوارد الصسادرات لتمويل

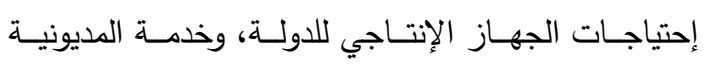

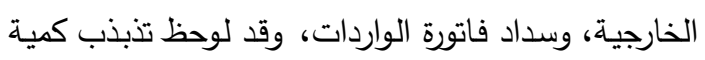

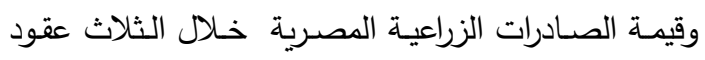
الماضية إذ إنخفضت قيمة الصادرات الزاعية المصرية من حوالي 507 مليون دولار كمتوسط للفترة (1986-1998) إلي حوالي 26.34 مليون دولار كمتوسط للفترة (19992016) ، في نفس الوقت الذي زادت فيه قيمة الواردات الزراعية من حوالي 3051 مليون دولار إلي حوالي 7948

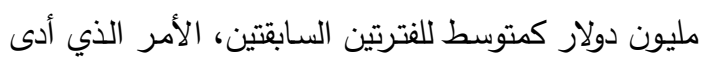

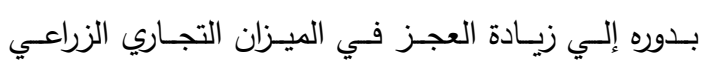
المصري من حوالي 2544 مليون دولار إلي قرابة 7922 مليون دولار (www.faostat.org). كما تلعب التجارة الخارجية دوراً لا يمكن الإستهانة به

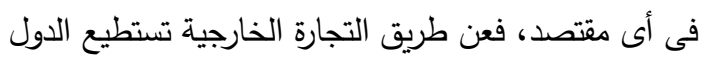

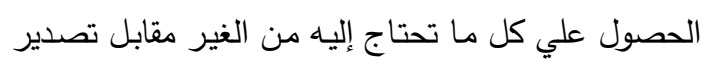

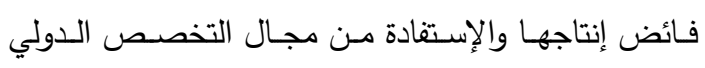
الذى تقوم أصـلا عليـهـ ، وبصـفة عامـة تسـاعد التجـارة

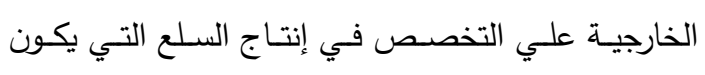

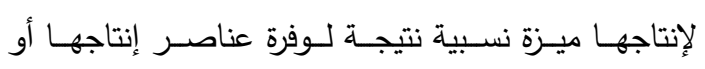

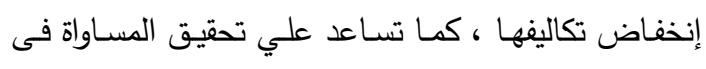

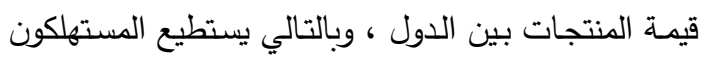
الحصول علي نفس المنتج بقيمة متقاربة أينما كانوا . وتتميز حياة الإنسان في هذا العصر بممارسة أنشطة

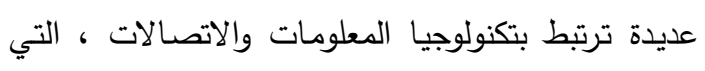
تلسم بالسرعة ووفرة المعلومات، و من بين مـا أفرزه هذا

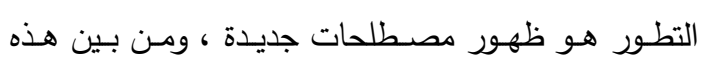

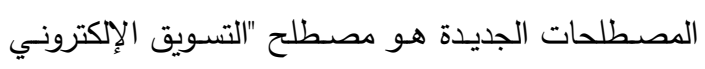
"الذي أصبح يتداول في الاستخدام العادي للأفراد. 


\section{E-marketing and means to develop Egyptian agricultural exports}

$$
\text { ثانيا : عينة البحث : }
$$

لتحليل الوضع الراهن لاستخدام التسويق الالكترونى

فى شركات تصدير الحاصلات الزراعية المصرية تم استخدام البيانات الاولية التى تم جمعها من خلال الاستبيان الذى تم تصميمه بحيث يحقق أهداف الدراسة ، حيث تم اختيار عينة عشوائية بسيطة تمثلت فى ثمانية وأربعون مفردة تمثل قرابة 34\% من مجتمع الدراستز وتم إختيار مفردات العينة من خلال المقابلة الثخصية مع دنع عدد من المصدرين أثناء حضورهم ورشة عمل تحت في عنوان " تفعيل التجارة الإكترونية فى مجال التصدير" التىى عقدت فى أبريل 2017 بمقر الغرفة التجارية بالأسكندرية بالتعاون والتتسيق بين شعبة الدصدرين بالغرفة التجارية ، بالتران

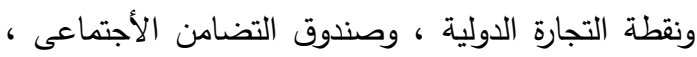

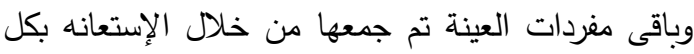

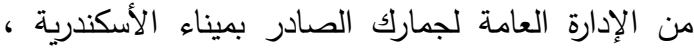
وإدارة الصادر بقرية البضائع بمطار النزهة بالأسكندرية،

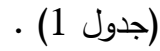

\section{النتائج البحثية ومناقشتها}

قسم (1): الوضع الراهن لاستخدام الوسائل التسويقية فى مصر فى تصدير الحاصلات الزراعية: يتتاول هذا القسم الوضع الراهن لاستخدام الوسائل التسويقية فى مصر فى تصدير الحاصلات الزراعية وذلك الك من خلال الأستبيان الذى جمع من عينة عشوائية بسيطة من الشركات التى تقوم بتصدير الحاصلات الزراعية .

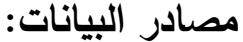
سوف يعتد البحث على البيانات الأولية أو القطاعية التى يمكن الحصـول عليهـا مـن خـلال تصـيم إسـتمارة إستبيان للوفـاء بـأغراض الدراسـة والتـى يتم مـن خلالهـا التعرف على أهم المعوقات والحلول المقترحة التي تواجها

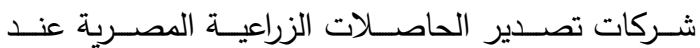

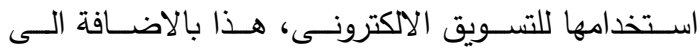
الاسـتعانة بـبعض المعلومـات التـى تتضــنها الـدوريات

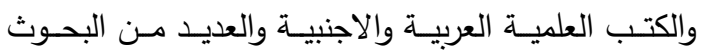

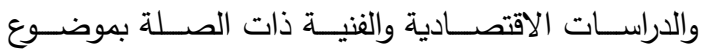
الدراسـة، كمــا سيتم الاسـتعانة بشـبكة المعلومـات الدوليـة الانترنت للحصول على المعلومات والبيانات ذات الصلة

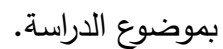

$$
\text { أولا : مجتمع البحث: }
$$

يمثل مجتمع البحث جميع شركات تصدير الحاصلات الزراعية والبالغ عددها وقت اجراء الدراسة 140 شركة

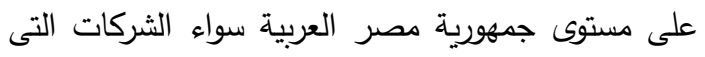
تستخدم الوسائل التقليدية أو المستخدمة الوسائل الاكترونية والتى لها موقع على شبكة المعلومات الدولية أو لها بريد الكترونى، وتم الحصول على عدد واسماء وعناوين تلك الثركات من خلال احصائيات شعبة المصدرين بالغرفة التجارية بالاسكندرية ، ودليل الصادرات الزراعية بالهيئة العامة للرقابة على الصادرات والواردات .

\begin{tabular}{|c|c|c|}
\hline النسبة \% & عدد المفردات & 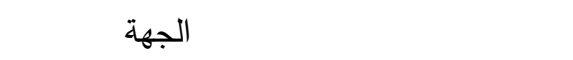 \\
\hline$\% 20.84$ & 10 & ورشة العمل بالغرفة التجارية \\
\hline$\% 52.08$ & 25 & الادراة العامة لجمارك الصادر ميناء الأسكندرية \\
\hline$\% 27.08$ & 13 & قرية البضائع بمطار النزهة \\
\hline 100 & 48 & 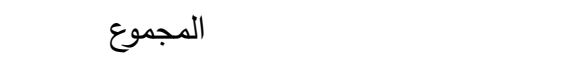 \\
\hline
\end{tabular}

جدول (1): توزيع مفردات العينة المختارة

المصدر : المقابلة الثخصية مع المبحوثين فى الأماكن المذكورة بالجدول . 


\section{Amal Elgabery, et al.,}

وعدم الالمام بكيفية استخدام الوسائل الالكترونية ، والى الى الذي

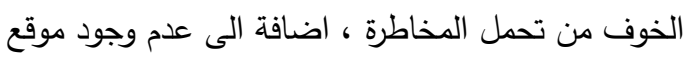

الكترونى على شبكة الانترنت يتم التعامل من خلالها .

وبسؤال المبحوثين السابقين عن خطتهم المستقبلية للتحول من الوسائل التقليدية الى الوسائل الالكترونية

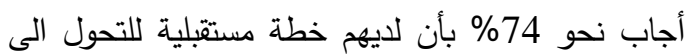

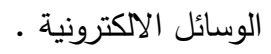

(2) الوضع الراهن لاستخذام الوسائل الاكترونية فى إعلى تصدير الحاصلات الزراعية :

باستعراض بيانات الجدول (3) الذى يوضح أهم نواحى استخدام التسويق الالكترونى فى تصدير الحاصلات الزراعية المصرية ، تبين من اراء المبحوثين

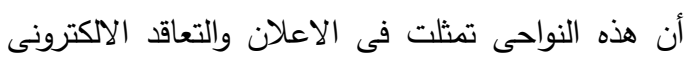
والثحن والدفع الالكترونى وخدمات العملاء (دعم فنى) التهات

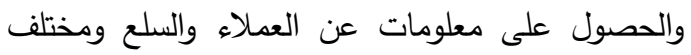
النواحى الخاصة بتصدير الحاصلات الزراعية .
أولاً: الوسائل التسويقية فى تصدير الحاصلات الزراعية المصرية : (1) الأهمية النسبية لاستخدام الوسائل التسويقية فى لمى تصدير الحاصلات الزراعية المصرية: تم الإستعانة بالبيانات الأولية المستخرجة من لصنايل استمارات الاستبيان التى تم جمعها من عينة عشوائية بسيطة من شركات تصدير الحاصلات الزراعية، وقد تبين من أجوبة المبحوثين (جدول 2) أن حوالى 37.8 يستخدمون الوسائل التقليدية والألكترونية فى تصدير منتجاتهم الزراعية ، يليها فى الأهية الوسائل التقليدية

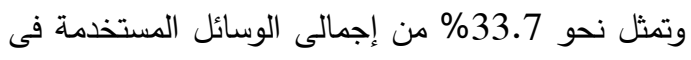

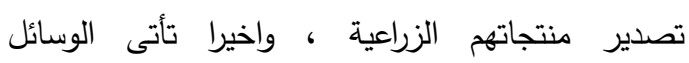
الالكترونية وتمثل نحو 28.4\% . وقد ذكر المبحوثين الذى يستخدمون الوسائل التقليدية

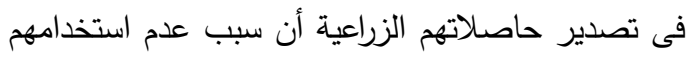

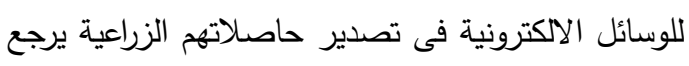
الى عدم مناسبة الوسيلة الالكترونية الى ما يتم تصديره ،

جدول (2): الأهمية النسبية لاستخدام الوسائل التسويقية فى تصدير الحاصلات الزراعية المصرية

\begin{tabular}{|c|c|c|}
\hline$\%$ & 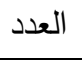 & نوع الوسيلة \\
\hline 37.8 & 28 & 1 - الوسائل التقليدية والإككترونية معا \\
\hline 33.7 & 25 & 2 - الوسائل التقليدية \\
\hline 28.4 & 21 & 3 - الوسائل الالكترونية \\
\hline
\end{tabular}

المصدر : جمعت وحسبت من بيانات عينة الدراسة.

جدول (3): الأهمية النسبية لنواحى استخدام التسويق الاكترونى فى تصدير الحاصلات الزراعية

\begin{tabular}{|c|c|c|}
\hline$\%$ & العدد العد & 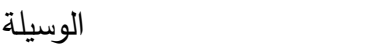 \\
\hline 27.2 & 31 & الاعلان \\
\hline 15.8 & 18 & التعاقد الالكترونى \\
\hline 13.2 & 15 & الثحن \\
\hline 9.6 & 11 & الدفع الالكترونى \\
\hline 11.4 & 13 & خذمات العملاء (دعم فنى) \\
\hline 22.8 & 26 & الحصول على معلومات \\
\hline
\end{tabular}

المصدر: جمعت وحسبت من بيانات عينة الدراسة. 


\section{E-marketing and means to develop Egyptian agricultural exports}

(4) الصادرات الزراعية المصرية التى تقوم شركات التصدير بتسويقها الكترونيا:

بإستعراض بيانات الاستبيان يتضح أن أهم السلع

الزراعية التى تقوم شركات تصدير الحاصلات الزراعية المصرية بتصديرها من خلال الوسائل الالكترونية تشمل صادرات سلع زراعية فى صورة مادة خام طازجة مثل الخضروات والفواكه الطازجة بأهمية نسبية بلغت حوالى راعلى

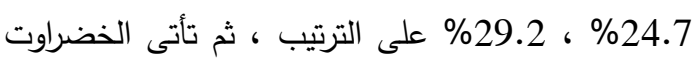

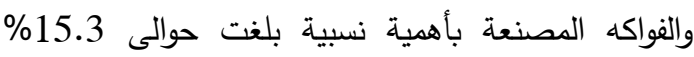

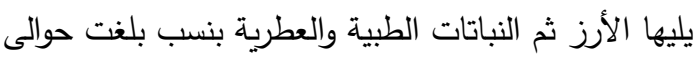
12.3 \% 18.5\% على الترتيب من إجمالى اصناف السلع الزراعية التى تقوم شركات تصدير الحاصلات الزراعية بتصديرها من خلال الوسائل الالكترونية (جدول
يتبين مما سبق أن وسيلة استخدام التسويق الالكترونى فى الاعلان جاءت فى المركز الأول بنسبة بلغت حوالى الى التئي

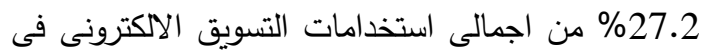

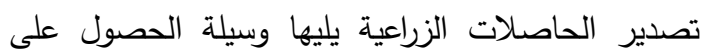
معلومات فى المركز الثانى بنسبة 22.8\% يليها وسيلة التعاقد الاكترونى بنسبة بلغت حوالى 15.8\% ثم كل من

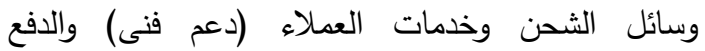

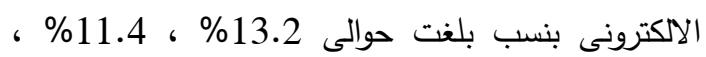
9.6 \% على الترتيب .

(3) الأهمية النسبية للشركات الزراعية المستخدمة لوسائل التسويق الألكترونى:

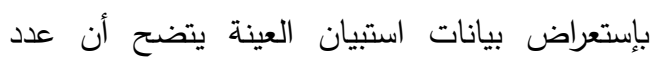

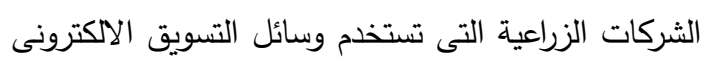

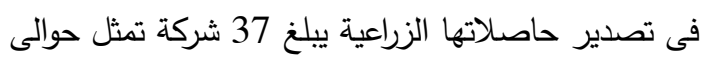
78 من إجمالى عدد شركات عينة الدراسة التى تقوم بتصدير الحاصلات الزراعية (جدول 4).

جدول (4): الأهمية النسبية للشركات الزراعية المستخدمة لوسائل التسويق الاكترونى

\begin{tabular}{|c|c|c|}
\hline 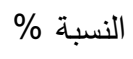 & 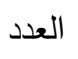 & 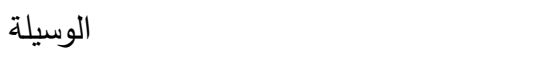 \\
\hline 78 & 37 & الثركات المستخدمة للوسائل الالكترونية \\
\hline 22 & 11 & الثركات غير المستخدمة للوسائل الالكترونية \\
\hline 100 & 48 & 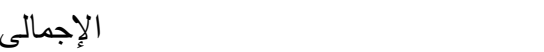 \\
\hline
\end{tabular}

المصدر: جمعت وحسبت من بيانات عينة الدراسة.

جدول (5): أهم الصادرات الزراعية المصرية التى يتم تصديرها من خلال الوسائل الاكترونية

\begin{tabular}{|c|c|c|}
\hline$\%$ & 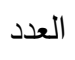 & نوع السلعة \\
\hline 24.7 & 16 & خضروات طازجة ("*) \\
\hline 29.2 & 19 & فواكه طازجة (**) \\
\hline 15.3 & 10 & الخضر والفواكه المصنعة \\
\hline 12.3 & 8 & 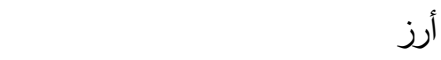 \\
\hline 18.5 & 12 & نباتات طبية وعطرية \\
\hline
\end{tabular}

*خضروات طازجة تشمل بطاطس - بصل - خيار -فلفل * * فواكه طازجة تشمل عنب - مانجو - موالح المصدر : جمعت وحسبت من بيانات عينة الدراسة. 
المصرية الأمر الذى يشير الى العناية بهذه الأسواق

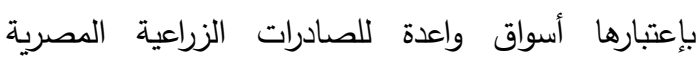
وخاصة ان مصر عضو فى اتفاقيسة الكوميسا . (6) أهم أسواق الدول المنافسة لصادرات مصر من السلع الزراعية من خلال التسويق الاكترونى:

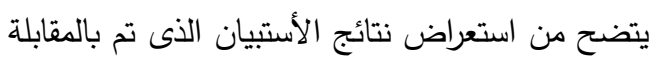

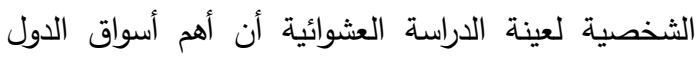

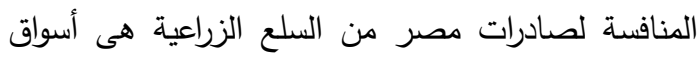

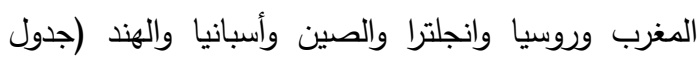

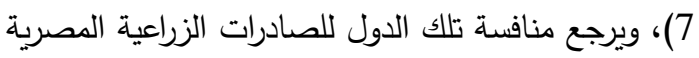

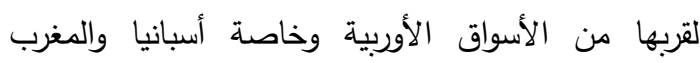

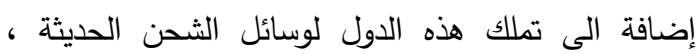

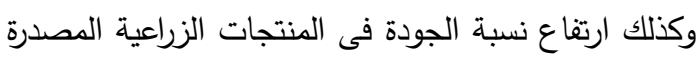

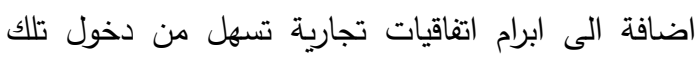

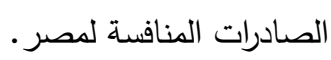

(5) أهم الأسواق المستوردة للحاصلات الزراعية المصرية عن طريق التسويق الالكترونى:

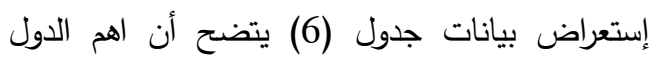

المستوردة للصادرات الزراعية المصرية التى يتم تسويقها

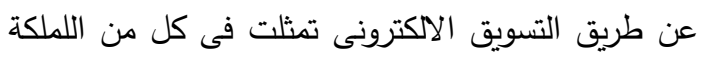
العربية السعودية والامارات العربية المتحدة وقطر ولبنان والاردن وروسيا وأسواق الاتحاد الاوروبى وأسواق أفريقيا . ويتبين من نفس الجدول أن أهم الاسواق المستوردة

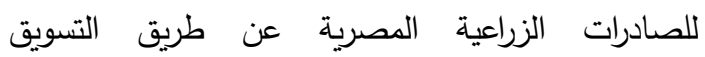
الالكترونى تمثلت فى كل من السعودية والامارات ولبنان والاردن والاتحاد الأوروبى وروسيا والأسواق الأفريقية بأهمية نسبية بلغت حوالى 20.7\% \% 18.9\% ، 16.9\% \%

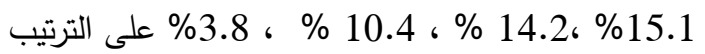
ويتبين مما سبق انخفاض الأهمية النسبية للأسواق الأفريقية كأسواق واعدة ومستوردة للصادرات الزراعية جدول (6): أهم الأسواق المستوردة للحاصلات الزراعية المصرية عن طريق التسويق الاكترونى

\begin{tabular}{|c|c|c|}
\hline$\%$ & العدد العد & البيان \\
\hline 20.7 & 22 & السعودية \\
\hline 18.9 & 20 & الامارات \\
\hline 16.9 & 18 & 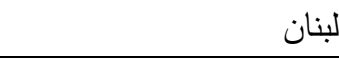 \\
\hline 15.1 & 16 & الأردن \\
\hline 14.2 & 15 & أسواق الاتحاد الاوروبى \\
\hline 10.4 & 11 & روسيا \\
\hline 3.8 & 4 & أسواق افريقيا \\
\hline
\end{tabular}

المصدر: جمعت وحسبت من بيانات عينة الدراسة.

جدول (7): أهم الدول المنافسة للصادرات الزراعية المصرية من خلال التسويق الاكترونى

\begin{tabular}{|c|c|c|}
\hline$\%$ & العدد & البيان \\
\hline 23.1 & 21 & المغرب \\
\hline 19.8 & 18 & روسيا \\
\hline 17.6 & 16 & اسبانيا \\
\hline 15.4 & 14 & انجلترا \\
\hline 13.1 & 12 & الهند \\
\hline 11.1 & 10 & الصين \\
\hline
\end{tabular}

المصدر: جمعت وحسبت من بيانات عينة الدراسة. 


\section{E-marketing and means to develop Egyptian agricultural exports}

هذه السلع الزراعية ، وجاء متغير السعر المناسب فى المرتبة الثانية بنسبة حوالى 18.5\% الأمر الذى يشير الى منافسة الصادرات الزراعية المصرية فى السوق العالمى نتجية لارتفاع أسعار الصادرات الزراعية المصرية مقارنة بمثيلتها من السلع المصدره من أسواق الدول المنافسة وهذا يتطلب اعادة النظر فى السياسة السعرية الزراعية المتبعة حتى يمكن الوصول بالصادرات الزراعية المصرية الى الاسواق العالمية بأسعار تتافسية تساعد الصادرات الزراعية المصرية الدخول الى الأسواق العالمية بنجاح ، وتأتى ميزة توفر الأنظمة الاككترونية المساعدة فى المرتبة الثالثة من الميزات التى تميز أسواق الدول المنافسة بنسبة حوالى الى 16.7\% ويرجع ذلك الى التقدم التكنولوجى الذى تتميز به الدول المنافسة مقارنة بالتكنولوجيا المستخدمة فى مصر كي ثم تأتى كل من ميزات وجود اتفاقيات مبرمة بين الدول المنافسة والدول المستوردة منها ، وشروط التعاقد ، وقرب المكان وموعد العرض فى المراتب التالية بنسب بلغت

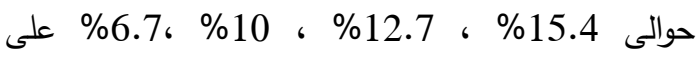
- الترتيب
وتم ترتيب تلك الدول المنافسة للصادرات الزراعية المصرية من خلال التسويق الالكترونى حيث تبين أن المغرب تأتى فى المركز الأول بنسبة حوالى 23.1\% يليها كل من روسيا واسبانيا فى المركز الثانى والثالث بنسبة حوالى 19.8\% ، 17.6\% على الترتيب ثم يليهم فى الأهمية كل من انجلترا والهند والصين بنسب حوالى

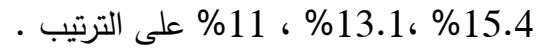

(7) أسباب تميز الدول المنافسة للصادرات الزراعية المصرية عن طريق التسويق الالكترونى من وجهة نظر المصدرين المبحوثين : بإستعراض بيانات الأستبيان يتضح أن أهم المميزات التى تتميز بها أسواق الدول المنافسة للصادرات الزراعية المصرية عن طريق التسويق الالكترونى مرتبة تنازليا وفقا لأهميتها النسبية موضحة بجدول (8) والذى يتضح منه أن المواصفات الجيدة للسلعة جاءت فى المرتبة الأولى من أهم المميزات التى تميز صادرات الدول المنافسة للصادرات الزراعية المصرية بنسبة بلغت حوالى 20\% مما يعنى اهتمام المصدرين الزراعيين المصرين بودة السلع المصدرة حتى يمكنها منافسة صادرات الدول المماثلة من

جدول (8): مميزات الدول المنافسة للصادرات الزراعية المصرية فى التسويق الاكترونى

\begin{tabular}{|c|c|c|}
\hline$\%$ & 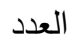 & 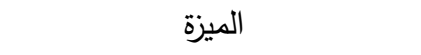 \\
\hline 20.0 & 30 & المواصفات الجيدة للسلعة \\
\hline 18.5 & 28 & السعر المناسب \\
\hline 16.7 & 25 & توفر الأنظمة الالكترونية المساعدة \\
\hline 15.4 & 23 & وجود اتفاقيات مبرمة بينهح \\
\hline 12.7 & 19 & شروط التعاقد \\
\hline 10.0 & 15 & 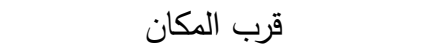 \\
\hline 6.7 & 10 & موعد العرض \\
\hline
\end{tabular}

المصدر : جمعت وحسبت من بيانات عينة الدراسة. 
وخاصة فى حالة توافر الطرق البرية الممهدة وتوافر

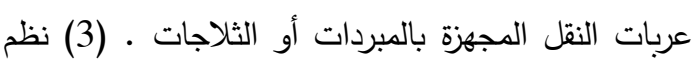
النقل عن طريق الجو وجاءت فى المرتبة الثالثة بعد النقل البحرى والنقل البرى بأهمية نسبية بلغت حوالى 15.2 الجى ويعتبر النقل الجوى من أغلى وسائل النقل حيث يتميز

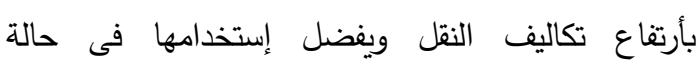
الحاصلات الزراعية سريعة التلف ذات القيمة المرتفعة مثل فئل

$$
\text { زهور القطف والزينة . }
$$

قسم (2): المشاكل التى تواجه شركات تصدير

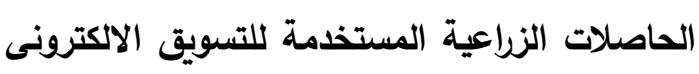

\section{والحلول المقترحة:}

تقسم المشاكل التى تواجه شركات تصدير الحاصلات

الزراعية عند استخدامها التسويق الاكترونى الى مشاكل

داخلية وأخرى خارجية كما يتضح من جدول (10) .
ثانياً: وسائل النقل المستخدمة لنقل الصادرات الزراعية المصرية وفقا للتسويق الاكترونى:

بإستعراض بيانات جدول (9) لتوضيح الأهية النسبية

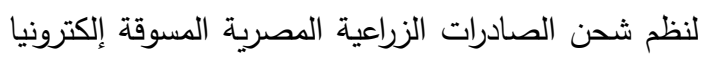
وفقا لأراء الدصدرين المبحوثين تبين أن: (1) نظم النقل عن طريق البحر جاءت فى المرتبة الأولى بنسبة حوالى لى ألى

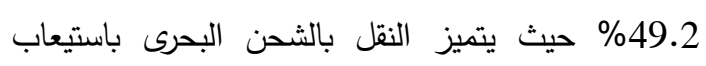
كميات كبيرة من السلع المصدرة وخاصة السلع كبيرة الحجم وغير سريعة التلف مثل محاصيل الحبوب ولكن يعاب على هذه الطريقة من الثحن البحرى أنها لا تصلح

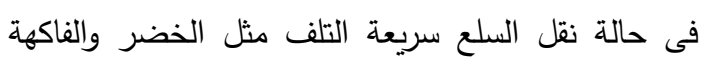
الطازجة وخاصة فى حالة طول مسافة النقل وعدم توفر

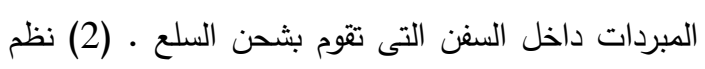

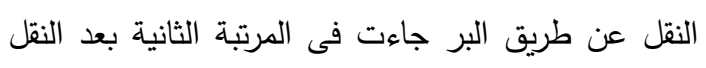

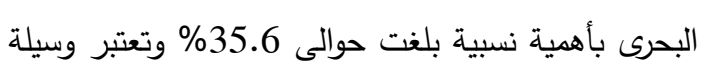
النقل البرى رخيصة الثن بالمقارنة بوسائل النقل الأخرى وتئي

جدول (9): وسائل نقل الصادرات الزراعية المصرية

\begin{tabular}{|c|c|c|}
\hline$\%$ & العدد العد & الوسيلة \\
\hline$\% 49.2$ & 29 & النقل عن طريق البحر \\
\hline$\% 35.6$ & 21 & النقل عن طريق البر \\
\hline$\% 15.2$ & 9 & النقل عن طريق الجو \\
\hline
\end{tabular}

المصدر : جمعت وحسبت من بيانات عينة الدراسة.

جدول رقم (10): أهم المشاكل الداخلية التى تواجه شركات تصدير الحاصلات الزراعية المصرية

\begin{tabular}{|c|c|c|}
\hline$\%$ & العدد & 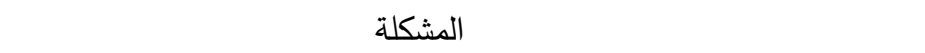 \\
\hline 15.2 & 14 & عدم أنتظام المواعيد \\
\hline 8.7 & 18 & سوء عمليات التداول \\
\hline 10.9 & 10 & عدم كفاءة مندوبى الثحن \\
\hline 17.4 & 16 & قلة امكانيات شركات الشحن للتعامل مع كافة أنواع واحجام السلع \\
\hline 12.0 & 11 & سوء النظام الادارى بشركات الثحن \\
\hline 16.3 & 15 & عدم توافر وسائل المحافظة على السلع من التلف حتى وصولها الى المستهلك \\
\hline 19.6 & 18 & قلة عدد خطوط الشحن \\
\hline
\end{tabular}

المصدر : جمعت وحسبت من بيانات عينة الدراسة. 


\section{E-marketing and means to develop Egyptian agricultural exports}

- - تطوير نظم الثحن الليكترونى وانتظام مواعيد الثحن

ويتم ذلك من خلال تدريب أفراد يكونوا مؤهلين لنظم

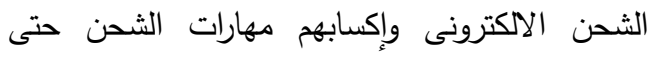

يمكن الانتهاء من شحن الصادرات الزراعية فى العيى

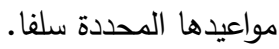

توفير شاحنات مجهزة بالمبردات حتى يمكن المحافظة على المنتجات الزراعية من التلف نتجية لسوء الظروف الجوية الاهتمام بالبنية التحتية التكنولوجية حيث يرتبط التطور فى استخدام التسويق الالكترونى بالتطور فى وسائل تكنولوجيا الاتصالات من أجهزة كمبيوتر وملحقاتها وفاكسات ووصلات الانترنت فائقة السرعة الأمر الذى يتطلب تدريب الأفراد على صيانة

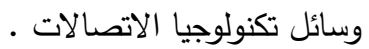

- تطوير النظام الأدارى بشركات الثحن حتيمكن ملاحقة كل ما هو جديد مما يساعد هذه الثركات فى لهى لهردي شحن المنتجات الزراعية بالطريقة السليمة وبعيدا عن الأخطاء الأدارية التى قد تتسبب فى تأخير شحن هذه باته الحاصلات مما يحمل الصصدرين غرامات تأخير بسبب عدم وصول صادراتهم الى الدول المستوردة فى الوقت المحدد وفقا لثروط العقد بين الطرفين .

ويشير الجدول رقم (11) إلى الأهمية النسبية للمقترحات الخاصة بحلول المشاكل الداخلية حيث يتبين أن تطوير الثاحنات الخاصة بشركات الشحن تمثل نحو 30.77، يليها فى الأهمية النسبية تطوير نظم الثحن الالكترونى وانتظام مواعيد الثحن بنسبة بلغت حوالى 26.92 \%، ثم يلى ذلك توفير شاحنات مجهزة بالمبردات بنسبة حوالى 19.23\% ، يلى ذلك الأهتمام بالبنية التحتية التكنولوجية بنسبة بلغت حوالى 12.82 \% وأخيرا جاء مقترح تطوير النظام الأدارى بشركات الثحن بأهية نسبية

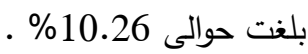

أولاً: المشاكل الداخلية والحلول المقترحة من وجهة

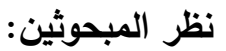

(1) المشاكل الاخلية التى تواجه شركات تصدير

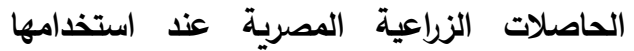
التسويق الاكترونى :

تبين من خلال أراء المبحوثين الذين شملهم الاستبيان أنه يمكن حصر تلك المشاكل وفقا لأهميتها النسبية كما يتضح من الجدول رقم (10) الذى يتضح من استعراض بياناته أن مشكلة قلة عدد خطوط الثحن تأتى فى المركز الأول من المشاكل الداخلية التى تواجهها شركات تصدير الحاصلات الزراعية بأهمية نسبية بلغت حوالى 19.6

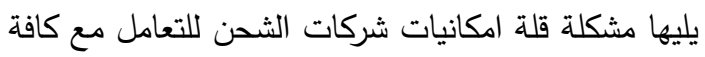
أنواع وأحجام السلع تأتى فى المركز الثانى بأهمية نسبية بلغت حوالى 17.4\% يليها مشكلة عدم توافر وسائل المحافظة على السلع من التلف حتى وصولها للمستهلك بنسبة16.3\% ويلى ذلك مشاكل عدم انتظام المواعيد ،

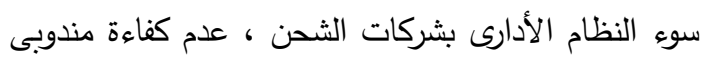

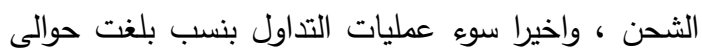

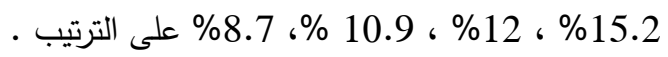
(2) الحلول المقترحات الخاصة بالمشاكل الاخلية من وجهة نظر المبحوثين : يتضح من خلال أراء المبحوثين من شركات تصدير الحاصلات الزراعية التى أشتملت عليها عينة الدراسة أن أن

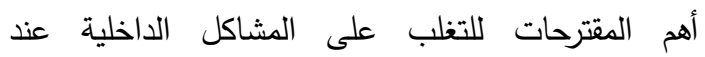
إستخدامهم التسويق الاككترونى فى تصدير منتجاتهم الزراعية كما هو مبين بجدول (11) تتحصر فى الآتى :

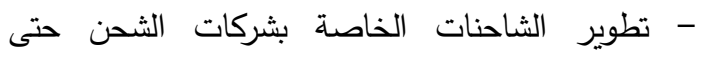

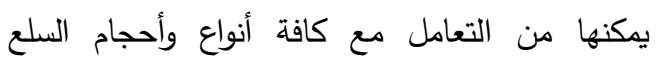
ويتحقق ذلك من خلال تقديم الدعم الكافى لشركات

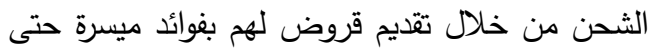
يمكن تطوير أسطول النقل البرى. 
Amal Elgabery, et al.,

جدول (11): أهم الحلول المقترحة للتظلب على المشاكل الداخلية التى تواجه شركات تصدير الحاصلات الزراعية عند تعاملهم مع التسويق الاككترونى.

\begin{tabular}{|c|c|c|}
\hline$\%$ & 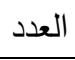 & مقترح الحل \\
\hline 30.77 & 24 & 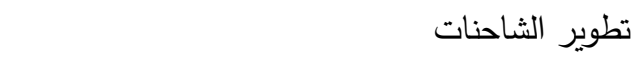 \\
\hline 26.92 & 21 & تطوير نظم الثحن الاككترونى وانتظام مواعيد الثحن \\
\hline 19.23 & 15 & توفير شاحنات مجهزة بالمبردات \\
\hline 12.82 & 10 & الاهتمام بالبنية التحتية التكنولوجية \\
\hline 10.26 & 8 & تطوير النظام الأدارى لشركات الثحن \\
\hline
\end{tabular}

المصدر : جمعت وحسبت من بيانات عينة الدراسة.

D.D.T: المصنع منه هذا النسيج كان معا ملا بمبيد

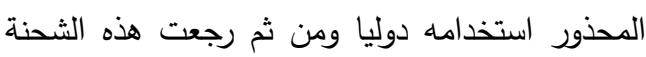

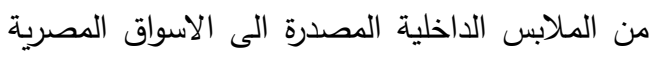
مرة أخرى . من المنابن

- المشاكل الخاصة بالحجر الزراعى والجمارك فى الدول

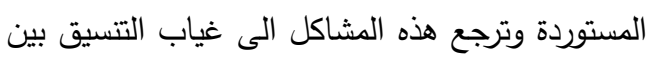

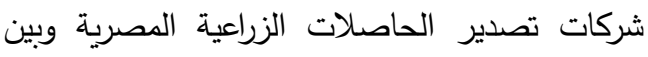
أجهزة الحجر الزراعى وإدارة الجمارك بتلك الدول

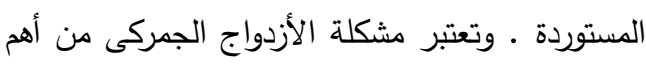

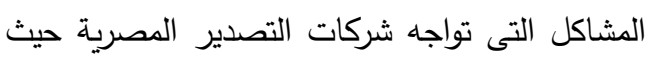

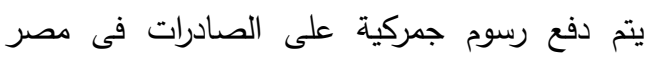
إضافة الى الرسوم الجمركية التى يتم دفعها فى الدولة

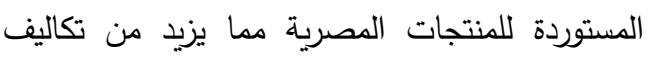
المصدرين مما يؤثر على أرباحهم ومن ثم عزوفهم

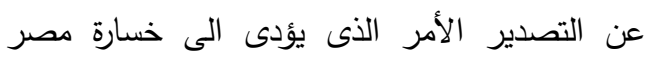
لاسواقها الخارجية. مشاكل قوانين الاستيراد التى تضعها الدول المستوردة

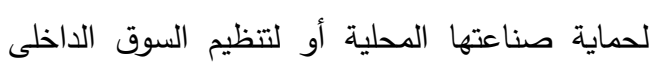

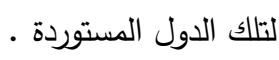

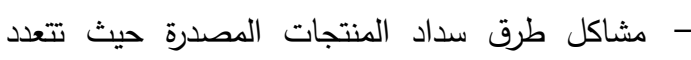

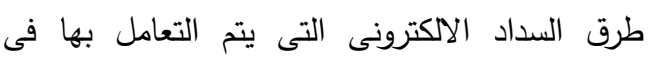

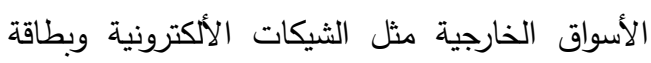
السداد الألكترونى وغيرها من طرق السداد الالكترونى الإنى ونظرا لعدم وعى معظم شركات تصدير الحاصلات الزراعية بهذه الطرق فهى تمثل عقبة لهذه الشركات
ثانياً: المشاكل الخارجية والعلول المقترحة من وجهة نظر المبحوثين:

(1) المشاكل الخارجية التى تواجه شركات تصدير التئن

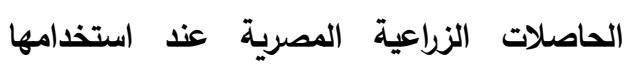

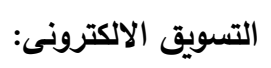

أتضح من اجابات المبحوثين الذين شملهم الاستبيان الأكروني

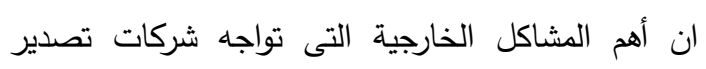

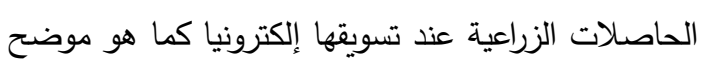

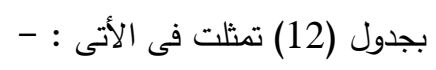

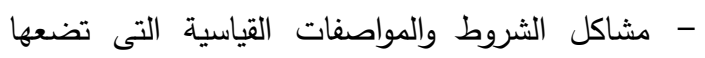

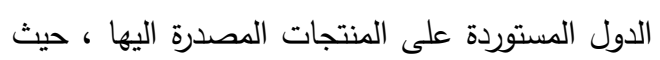

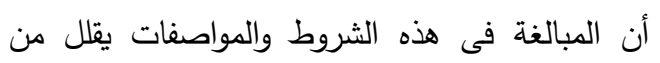

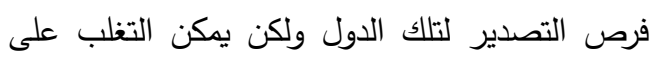
هذه المشكلة من خلال تحسين جودة المنتجات المصرية المصدرة وتوعية المصدرين المصرين بأهمية هذه الثروط والمواصفات القياسية للسلع الزراعية المصدرة الى للأسواقالعالمية وعمل اتفاقيات تجارية بين مصر وبين الدول التى تضع هذه الشروط

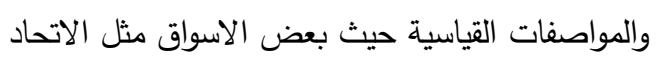
الاوروبى تثترط الحصول اليورو جاب وهى الثهادة

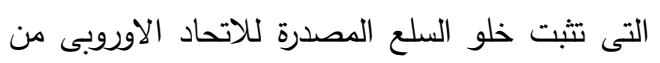

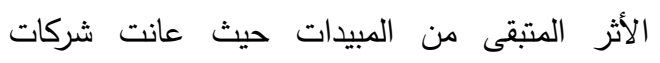
التصدير المصرية للملابس الجاهزة من هذه المشكلة

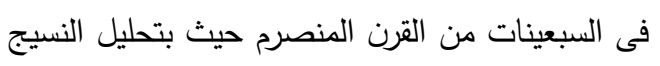

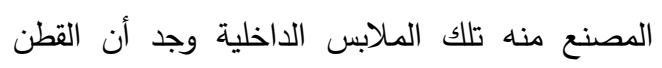




\section{E-marketing and means to develop Egyptian agricultural exports}

والمواصفات القياسية وطرق سداد المنتجات الزراعية

المصدرة والنقل والثحن بأهمية نسبية بلغت حوالى والى

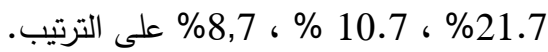

(2) الحلول المقترحات الخاصة بالمشاكل الخارجية من وجهة نظر المبحوثين :

يتضح من اجابات المبحوثين الذين شملهم الأستبيان

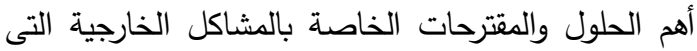
تواجه شركات تصدير الحاصلات الزراعية عند تسويقها الكترونيا كما هو موضح بجدول (13) تمثلت فى الآتى : - الاهتمام بجودة المنتجات الزراعية المصدرة من خلال الاهتمام بالشروط والمواصفات القياسية للسلع المصدرة كأحد متطلبات السوق العالمى ، وجدير بالذكر أن

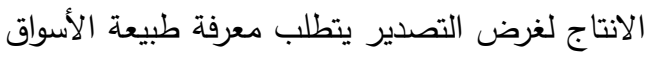

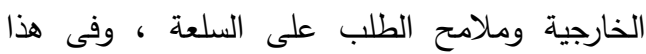
الصدد تجدر الأشارة الى أن تزايد المنافسة فى الفى وفئ الأسواق المحلية والدولية يتطلب تبنى اسلوب فلسفة إدارة الجودة Total Quality Management من الأبل خلال الاهتمام بحختف العمليات التسويقية بهدف دعم القدرة التنافسية وزيادة النصيب السوقى والتحسين المستمر لجودة المنتجات الزراعية وزيادة الصادرات .
لعدم ثقتهم فى التعامل بهذه الطرق مما يجعلهم يقومون بالاتفاق مع شريك أجنبى يعمل بالنظام

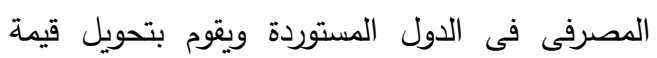
معاملات الصادرات الزراعية المصرية الى شركات التصدير المصرية مقابل عمولة معينة ممايزيد من تكلفة صادرات المنتجات الزراعية، إضافة الى إحتمال تعرضهم للنصب والاستغلال من هذا الشريك الأجنبى. - قلة توافر وسائل النقل الحديثة الدجهز بالدبردات خاصة فى ظل طول مسافة النقل وطول الفترة الزمنية حتى تصل المنتجات الزراعية المصدرة الى تلك الدول المستوردة ، ومن ثم امكانية عدم دخول الصادرات الزراعية المصرية الى أسواق تلك الدول ومثال ذلك ما حدث للصادرات الزراعية المصرية عام 2010 حينما تم رجوعها من الأتحاد الأوروبى نظرا لأصابتها

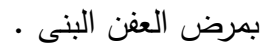
وتشير بيانات الجدول التالى الى الأهمية النسبية لتلك المشاكل الخارجية وفقا لأراء المبحوثين من عينة الدراسة ويتضح من الجدول السابق أن مشكلة قوانين الاستيراد

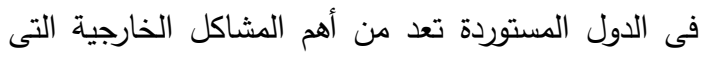
تواجه شركات تصدير الحاصلات الزراعية بأهمية نسبية بلغت 31.5 \% يليها مشكلة الحجر الزراعى والجمارك بنسبة حوالى 27.2 \% ثم كل منمشاكل الشروط

جدول (12): أهم المشاكل الخارجية التى تواجهها شركات تصدير الحاصلات الزراعية المصرية التى تم الأتفاق على تسويقها الكترونيا

\begin{tabular}{|c|c|c|}
\hline$\%$ & 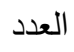 & 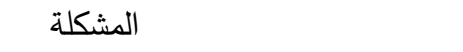 \\
\hline 21.7 & 20 & الشروط والمواصفات القياسية \\
\hline 27.2 & 25 & الحجر الزراعى والجمارك \\
\hline 31.5 & 29 & قوانين الاستيراد \\
\hline 10.7 & 10 & طرق سداد المنتجات الزراعية المصدرة \\
\hline 8.7 & 8 & النقل والثحن \\
\hline
\end{tabular}

المصدر : جمعت وحسبت من بيانات عينة الدراسة. 
Amal Elgabery, et al.,

جدول (13): أهم الحلول المقترحة للتفلب على المشاكل الخارجية التى تواجه شركات تصدير الحاصلات الزراعية عند

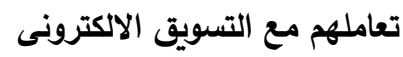

\begin{tabular}{|c|c|c|}
\hline$\%$ & 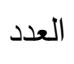 & مقترح الحل \\
\hline 28.38 & 21 & الاهتمام بجودة الهنتجات الزراعية المصدرة \\
\hline 20.27 & 15 & تدريب أفراد الحجر الزراعى والجمارك \\
\hline 17.57 & 13 & قوانين الحد من الاستيراد فى الدول المستوردة \\
\hline 12.16 & 9 & تدريب الأفراد القائمين على التصدير الالكترونى \\
\hline 21.62 & 16 & توفير وسائل النقل والثحن الدجهزة بالمبردات \\
\hline
\end{tabular}

المصدر : جمعت وحسبت من بيانات عينة الدراسة.

الالكترونى المناسبة لهم مما يزيد من تعاملاتهم فى

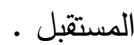

- يجب توفير وسائل النقل والثحن المجزة بالمبردات الحديثة حتى يمكن الحفاظ على جودة المنتجات

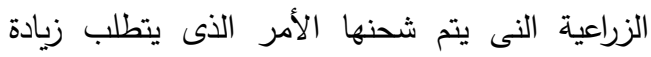

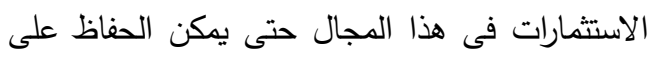

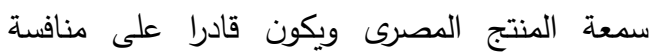
المنتجات المصدرة المثيلة التى تتطلب شروطا

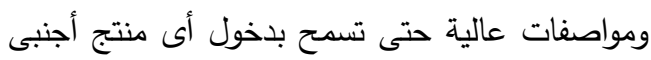

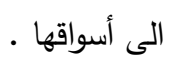

ويشير الجدول التالى إلى الأهمية النسبية للمتترحات الخاصة بحلول المشاكل الخارجية وقد تبين أن الاهتمام الاهية لهنية لمترهات بجودة المنتجات الزراعية المصدرة جاءت فى المرتبة الأولى من حيث الأهمية النسبية ومثلت نسبة 28.38\% يليها فى الأهمية النسبية توفير وسائل النقل والثحن المجزة بالمبردات بنسبة بلغت حوالى 21.62 \% ثم يلى الأى

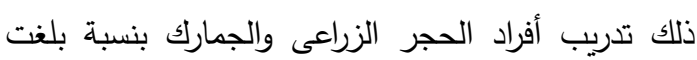

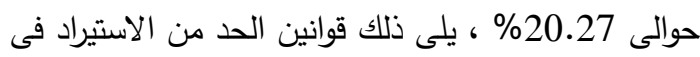

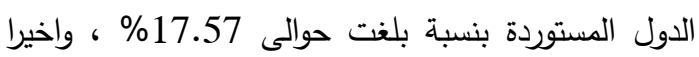

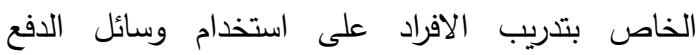

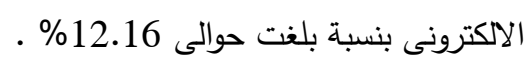

- تدريب أفراد الحجر الزراعى والجمارك حتى يمكنهم

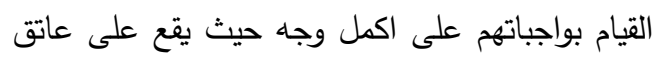
جهاز الحجر الزراعى دخول السلع المستوردة فإذا لم يتم الكشف عليها بطريقة جيدة يكون هناك أحتمال

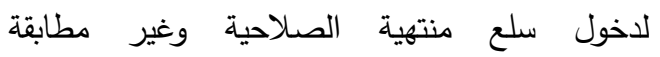

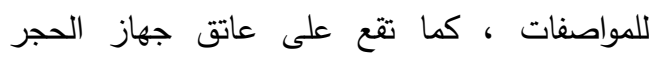

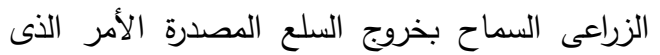

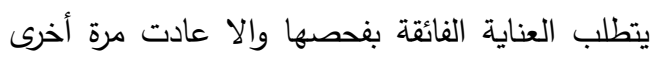

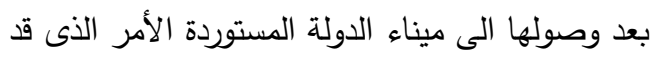

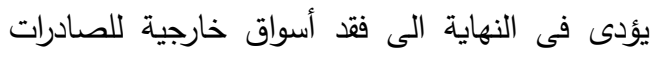
الزراعية المصرية . - قوانين الحد من الاستيراد فى الدول المستوردة حيث

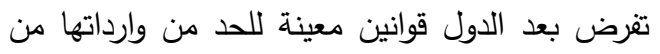

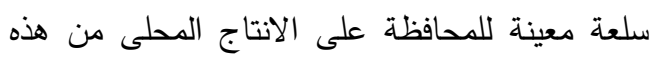
السلعة أو لحماية صناعة ناشئة قائمة على استخدام هذه السلعة ، ومن ثم فإن التعرف على تلك القوانين يفيد مصدرى هذه السلعة من شركات تصدير الحاصلات الزراعية فى البحث عن دول مستوردة أخرى أقل تعقيدا من حيث القوانين المفروضة على لعى دولى

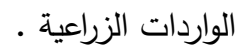
تدريب الأفراد القائمين على التصدير الالكترونى الإدئ

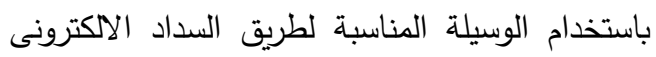

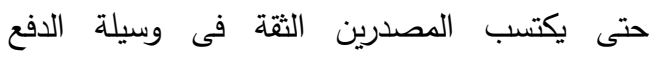




\section{E-marketing and means to develop Egyptian agricultural exports}

- مساعدة صغار ومتوسطى الزراع على تجميع الاستغلال الزراعى واتباع الممارسات الزراعية الجيدة طوال مراحل الانتاج وذلك لاستيفاء الشروط والمواصفات الأوربية والدولية للتصدير (يوروجاب - جلوبال جاب) • - ضرورة تطبيق برامج مكافحة فعالة لمكافحة الآفات الزراعية خاصة ذباب الخوخ والفاكهة .

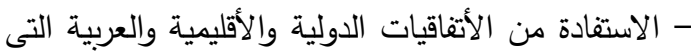
تشارك فيها مصر (منظمة التجارة العالمية - منظمة التجارة الحرة العربية الكبرى - الكوميسا - الأتحاد الأوبى ) وذلك علاوة على الأتفاقيات والبروتوكلات الثنائية بين مصر والدول الأخرى مثل روسيا والصين . - انشاء مركز متخصص لفحص الصادرات المصرية معتمد من الجهات العالمية للاعتماد - تطبيق نظام ذكى لمعلومات السوق يوفر كافة البيانات عن السوق وعلى الأخص المستوردين حول العالم ويمنح ترتيب للمستوردين ذوى المصداقية فى التعامل . - اعداد الحملات الترويجية المتخصصة داخل وخارج مصر للتعريف بالمنتج المصرى والترويج له . - رفع الحظر عن الصادرات الزراعية المصرية بالبحرين والكويت يزيد من فرص تتمية الصادرات . - تشجيع الاستثمار فى الأساليب التسويقية مثل تطوير وسائل النقل الداخلى وأستخدام العربات المتطورة المجهزة بالثلاجات للاسراع فى عملية النقل وحماية السلع المسوقة من الظروف الجوية غير الملائمة واستخدام التكنولوجيا الحديثة فى الشحن والتثريخ • - ضرورة اتباع تسجيل الكود الترقيمى على كل عبوة مصدرة للخارج بطريقة الثرائط الممغنطة تترجم الى بيانات متعارف عليها مطلوبة تساعد على سرعة التداول والتحاسب والحسابات والقيد وبيانات التخزين الألكترونى. - الأخذ بالمعايير البيئية فى مجال الصناعات الزراعية والغذائية والتصديرية وهو ما يعرف بنموذج ( ISO 9000) ، ويتطلب ذلك أستخدام الأسمدة الكيماوية

والمبيدات والتوسع فى أستخدام المكافحة الحيوية . - أن يكون الانتاج للتصدير هدفا عاما وشاملا لجميع المنتجين الزراعيين بمعنى ان يكون ذلك لكل ما ينتج
قسم (3) : سبل تنمية الصادرات الززاعية المصرية

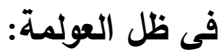
يتضمن هذا القسم بعض السبل لتتمية الصادرات الزراعية المصرية فى إطار العولمة من خلال الأستعانة ببعض الدراسات والبحوث التى أهتمت بهذا المجال، ونظر للتشابه الكبير فيما بين المستخلصات العامة التى يمكن الخروج بها من النتائج وما آلت إليه هذه الدراسات السابقة وفى ضوء ما ورد بالدراسات السابقة لهذه الدراسة يمكن وضع بعض السبل التى قد يكون لها أثرها الأيجابى فى تنمية الصادرات الزراعية المصرية للسوق العالمى كما ليصى - اتخاذ عدد من التدابير المشجعة لزيادة الصادرات المصرية والتى تتمثل فى تشريعات واجراءات مؤسسية تدعم مناخ الاعمال بشكل عام مثل مراجعة التشريعات المنظمة لقانون ولائحة الاستيراد والتصدير ،تبسيط اجراءات التصدير والاستيراد - دراسة توجهات الطلب العالمى لتحديد القطاعات التصديرية الواعدة والمستقبلية . - العمل على بناء وتتمية القدرات التصديرية للمصدرين المصريين من خلال وضع وتقديم برامج الدعم الفنى لتطوير المنشأت للتصدير - وضع منظومة متكاملة لمتابعة وتقييم اداء كافة الجهات التابعة والمعنية بالتصدير وقياس الأداء والنتائج للعمل وصله على التحسين المستمر - لع - تتظيم ووضع خطط المشاركة المصرية فى المعارض الدولية - اعداد البرامج التدريبية للمصدرين المصريين على مفي مفاهيم التجارة الإكترونية والتسويق الالكترونى وذلك وفقا لأفضل المعايير والمواصفات القياسية لضمان التوافق مع متطلبات واشتراطات الدول المستوردة . - الاستفادة من المزايا النسبية والتتافسية التى تتمتع بها مصر فى العديد من الحاصلات الزراعية خاصة المحاصيل البستانية من الخضر والفاكهة والحاصلات الزراعية غير التقليدية مثل النباتات الطبية والعطرية وزهور القطف . 


\section{Amal Elgabery, et al.,}

جابر احمد بسيونى (2003) ، محددات الطلب الخارجى

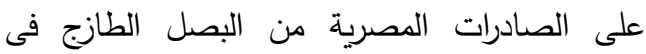

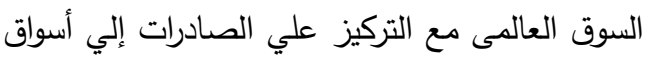

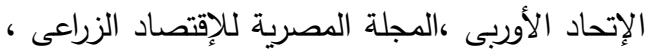
المجلد الثالث عشر ،العدد الأول ، مارس.

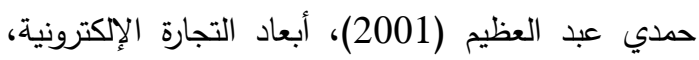

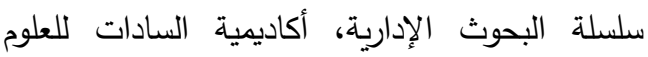
الإدارية، عدد (3).

شحاتة عبد المقصود غنيم \& سمير أنور متولى (32012)،

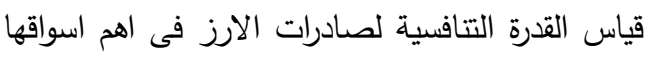

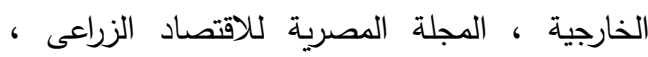
المجلد الثانى والعشرون ، العدد الثانى . شريف عبد الرازق شعيرة (2011) ، مشكلات تطبيق التجارة الإكترونية في مجال تصدير المنتجات

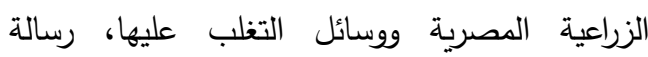
دكتوراه، قسم الاقتصاد اتلزراعي، كلية الزراعة ، جامعة دمنهور - دان.

عباس أبو ضيف (2008) ، دراسة اقتصادية لتتمية

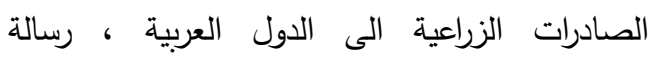

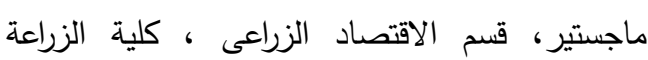

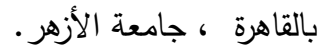

رانيا عبد الفتاح الثاعر (2012)، دراسة تحليلية للصادرات الدصرية من البرتقال فى السوق العالمى ،

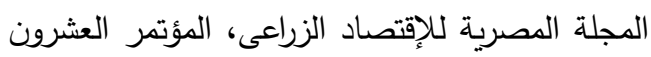
للاقتصاديين الزراعيين.

الموقع الإلبكتروني ل لمنظمة الأغذية والزراعة .(www.faostat.org)
من السلع الزراعية وليس فقط الجزء الذى يصدر ، أى الى

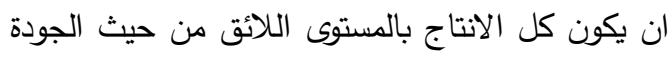
والسعر قادرا على المنافسة فى الاسواق العالمية فليست الصادرات فقط هى التى تدخل فى منافسة عالمية وانما ايضا ما يباع من المنتجات المحلية قى السوق المحلية خاصة بعد تحرير التجارة ورفع القيود على الواردات

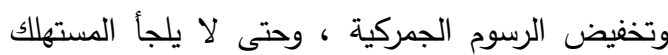

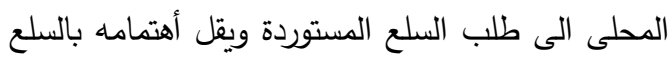

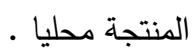

- الوفاء بمتطلبات الجودة بإعتبارها من أهم عناصر وبناء

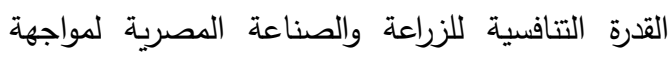
التحديات التى يتعرض لها المنتج الدصرى فى الأسواق

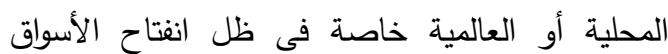
والتسابق الذى تثهده لإرضاءالمستهلك وتوفير متطلباته

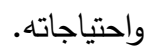

\section{المراجع}

إبراهيم العيسوي (2001)، التجارة الإكترونية ، المكتبة

$$
\text { الأكاديمية ، القاهرة. }
$$

ألفت على حسن ملوك (2003) ، أثر المتغيرات

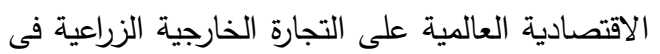

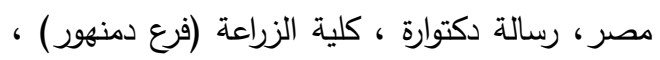

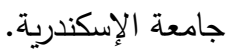
جابر أحمد بسيوني (2007)، الإتجاهات الحديثة في إدارة

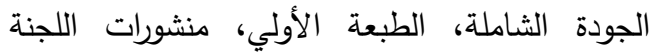
الثُعبية العامة للثقافة والإعلام ، طرابلس، ليبيا. 


\title{
E-marketing and means to develop Egyptian agricultural exports
}

\section{E-MARKETING AND MEANS TO DEVELOP EGYPTIAN AGRICULTURAL EXPORTS}

\author{
Amal Elgabery( ${ }^{(1)}$, G. Bassyouni( ${ }^{(2)}$, A. Al-Seify ${ }^{(1)}$ and Olivia Saleh ${ }^{(1)}$ \\ (1) Dept. of Economics and Agricultural Business - Faculty of Agriculture - Alexandria University \\ (2) Dept. of Agricultural Economics - Faculty of Agriculture (Saba Pasha) - Alexandria University
}

\begin{abstract}
The research aims to study the importance of e-marketing and ways of developing Egyptian agricultural exports. In order to analyze the current situation of the use of e-marketing in the Egyptian agricultural export companies, preliminary data collected through the questionnaire was used to achieve the objectives of the study. The main results of the study were: $37.8 \%$ of the respondents use traditional and electronic means to export their agricultural products, followed by traditional means, representing about $33.7 \%$ of the total means used in the export of their agricultural products. finally, electronic means represent about $28.4 \%$.

The respondents, who use traditional methods in exporting their agricultural crops mentioned that the reason for not using electronic means to export their agricultural crops is due to the lack of suitable electronic means to export them, lack of knowledge of how to use electronic means, fear of risk tolerance, an online website is handled through it. It also found that the most important aspects of the use of e-marketing in the export of Egyptian agricultural crops were in advertising, e-contracting, shipping, e-payment and customer services (technical support) and obtaining information about customers and commodities and various aspects of the export of agricultural crops. It is clear that the number of agricultural companies using electronic marketing methods in exporting their agricultural crops is 37 companies representing about $78 \%$ of the total number of sample companies that study the export of agricultural crops.

The most important agricultural commodities exported by Egyptian export companies through electronic means include the export of agricultural commodities in the form of raw materials such as vegetables and fresh fruits with a relative importance of about $24.7 \%$ and $29.2 \%$ respectively, followed by vegetables and processed fruits with relative importance of about $15.3 \%$, followed by rice, medicinal and aromatic plants, which accounted for about $12.3 \%$ and $18.5 \%$, respectively, of the total agricultural commodities exported by electronic export companies. The most important import markets for Egyptian agricultural exports through electronic marketing were Saudi Arabia, UAE, Lebanon, Jordan, European Union, Russia and African markets with relative importance of 20.7\%, 18.9\%, 16.9\%, 15.1\%, 14.2\%, 10.4\% and $3.8 \%$ respectively. It is noteworthy that the relative importance of African markets as a promising and imported market for Egyptian agricultural exports is low, indicating that these markets are considered as promising markets for Egyptian agricultural exports, specially that Egypt is a member of the COMESA agreement.

The studt showed the internal and external problems faced by Egyptian agricultural export companies when using e-marketing and the main proposals to overcome these internal and external problems when using e-marketing in the export of their agricultural products.

The research showed some means to develop Egyptian agricultural exports in the light of globalization so that it can compete with similar exports from the competing countries.
\end{abstract}

Key words: E-marketing - development of Egyptian agricultural exports - World markets.

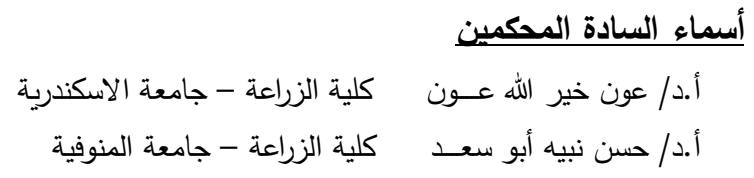


Amal Elgabery, et al., 